Article

\title{
Lignin Nanoparticle-Coated Celgard Separator for High-Performance Lithium-Sulfur Batteries
}

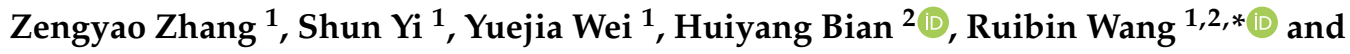 \\ Yonggang Min ${ }^{1, *}$ \\ 1 School of Materials and Energy, Center of Emerging Material and Technology, Guangdong University of \\ Technology, Guangzhou 510006, China; gdjy_zzy@163.com (Z.Z.); 13290065303@163.com (S.Y.); \\ wyj20190726@163.com (Y.W.) \\ 2 Jiangsu Provincial Key Laboratory of Pulp and Paper Science and Technology, Nanjing Forestry University, \\ Nanjing 210037, China; hybian1992@njfu.edu.cn \\ * Correspondence: wang.rb@gdut.edu.cn (R.W.); ygmin@gdut.edu.cn (Y.M.); \\ Tel.: +86-020-3932-2570 (R.W. \& Y.M.)
}

Received: 4 August 2019; Accepted: 22 November 2019; Published: 27 November 2019

check for updates

\begin{abstract}
Tremendous efforts have been made toward the development of lithium-sulfur (Li-S) batteries as one of the most reasonable solutions to the rapidly increasing demand for portable electronic devices and electric vehicles, owing to their high cost-efficiency and theoretical energy density. However, the shuttle effect caused by soluble polysulfides is generally considered to be an insurmountable challenge, which can significantly reduce the battery lifecycle and sulfur utilization. Here, we report a lignin nanoparticle-coated Celgard (LC) separator to alleviate this problem. The LC separator enables abundant electron-donating groups and is expected to induce chemical binding of polysulfides to hinder the shuttle effect. When a sulfur-containing commercially available acetylene black (approximately $73.8 \mathrm{wt} \%$ sulfur content) was used as the cathode without modification, the Li-S battery with the LC separator presented much enhanced cycling stability over that with the Celgard separator for over 500 cycles at a current density of $1 \mathrm{C}$. The strategy demonstrated in this study is expected to provide more possibilities for the utilization of low-cost biomass-derived nanomaterials as separators for high-performance Li-S batteries.
\end{abstract}

Keywords: lignin nanoparticles; separator; Li-S batteries; biomass; acid hydrotrope

\section{Introduction}

With the drastic growth of portable electronic devices and electric vehicles, the interest on rechargeable energy storage systems with high energy density, high power density, and long lifetime [1-3] has rapidly increased. Among the available options, lithium-sulfur (Li-S) batteries have been regarded as one of the most promising energy storage devices in the near future due to their high specific energy ( $\left.2500 \mathrm{Wh} \cdot \mathrm{kg}^{-1}\right)$ and theoretical specific capacity $\left(1675 \mathrm{mAh} \cdot \mathrm{g}^{-1}\right)$. However, the commercialization of Li-S batteries is still hindered by many technical challenges such as the shuttle effect caused by soluble polysulfides [4], volume expansion of sulfur during the charge/discharge process [5], low electrical conductivity of sulfur, etc. [6-8]. To facilitate the development of the $\mathrm{Li}-\mathrm{S}$ system, it is therefore crucial to alleviate the shuttle effect and improve the conductivity of the sulfur cathode.

In recent years, impregnating sulfur into tailored porous/hierarchical/nano-architectured carbon matrixes [9-11] and compositing conducting polymers (such as polyaniline [12], poly(N-methylpyrrole) [13], etc.) or metal organic framework/metal sulfides (oxide) [14-18] are the mainstream solutions to addressing these issues. Although these techniques can provide valuable 
insights into exploring high-performance Li-S batteries with impressive capacity and cycling stability, the use of expensive components/equipment and complex operations remain the major bottlenecks to wide utilization.

In this context, rational design of the structure and/or composition of separators is recognized as one of the most efficient solutions. Recently, intensive efforts have focused on modifying the commercial porous membranes (e.g., polypropylene [2,19,20], polyethylene [21,22], Nafion [23,24], glass fibers [25], etc. [26]) to provide new perspectives. These composite separators can serve as the electronic insulator among electrodes and influence the transportation of polysulfides. However, although these studies have shown pronounced improvements, some crucial issues remain to be resolved: (1) most ingredients used for the fabrication of the above separators are non-renewable; (2) energy-intensive processes, such as high-temperature carbonization and electrospinning, are included. Developing a low-cost and renewable biomass-modified separator therefore seems to be urgent. Inspired by the blossoming $\mathrm{f}$ research activities centered on the continued push for cheaper and more sustainable chemistries of biomass processing [27-29], low-cost lignin that can be greenly processed is expected to be a promising reinforcing agent for the separator of Li-S batteries.

Here, we report a simple strategy using a lignin nanoparticle (LNP)-coated Celgard (LC) membrane as a novel separator for $\mathrm{Li}-\mathrm{S}$ batteries. The low cost and abundant quinone of lignin engender a versatility for its application in diverse technologies such as sensors [30,31], solar cells [32], supercapacitors [33,34], and lithium-ion/sodium-ion batteries [35,36]. Thanks to their good dispersity [28,29], LNPs are easily deposited on a conventional Celgard separator by simple filtration to obtain a composite separator. When used in Li-S batteries, LNPs can chemically alleviate the polysulfides' diffusion, thereby significantly suppressing the polysulfides' shuttle, resulting in ultrahigh coulombic efficiency. Meanwhile, the quinone in LNPs can absorb electrons and release protons to facilitate the transport of lithium ions which guarantees a long lifecycle and good rate capability of the Li-S battery. These encouraging results pave the way for a viable conversion of biomass-derived lignin into a sustainable and low-cost functional material for energy storage.

\section{Materials and Methods}

\subsection{Preparation of Lignin Nanoparticles (LNPs)}

Lignin nanoparticles were produced according to previously reported procedures $[37,38]$ in which the feedstock and acid hydrotrope were aspen wood sawdust and benzenesulfonic acid (B-acid), respectively. Briefly, $40 \mathrm{~g}$ of B-acid was mixed with $10 \mathrm{~g}$ of deionized (DI) water in a $100 \mathrm{~mL}$ flask. Then the mixture was heated to $80^{\circ} \mathrm{C}$ under mechanical stirring (200 rpm) until a clear solution was achieved, followed by the addition of $2.5 \mathrm{~g}$ (oven-dry weight) of cypress sawdust. The reaction was maintained at $80{ }^{\circ} \mathrm{C}$ for $20 \mathrm{~min}$ under mechanical stirring $(500 \mathrm{rpm})$. At the end of the reaction, the flask was removed from the heat source and the resultant mixture was vacuum filtrated immediately. The filtrate was dialyzed against DI water for 3 days and then oven-dried at $60{ }^{\circ} \mathrm{C}$ for $12 \mathrm{~h}$ to obtain LNPs.

\subsection{Fabrication of LNP-Coated Celgard (LC) Separator}

The LC separator was fabricated according to Tang's [21] study. In brief, LNPs were first dispersed in ethanol $(80 \%(v / v), \mathrm{pH}$ value was adjusted to 9 by adding a desired amount of $\mathrm{NaOH})$ under magnetic stirring until a clear solution was obtained. Second, the resultant solution was subjected to vacuum filtration using the Celgard membrane (Celgard 2400, Celgard Company, Charlotte, NC, USA). Subsequently, the filter cake was vacuum-dried at $50{ }^{\circ} \mathrm{C}$ overnight with Celgard to give an LC separator of approximately $0.72 \mathrm{~g} \cdot \mathrm{cm}^{-2}$ at the LNP loading. The facile fabrication of the LC separator is schematically illustrated in Figure 1. In addition, to investigate the adhesion of LNPs on the LC separator, a peeling test was utilized according to previous research $[39,40]$ and the results indicated that LNPs have good adhesion on the Celgard substrate. 


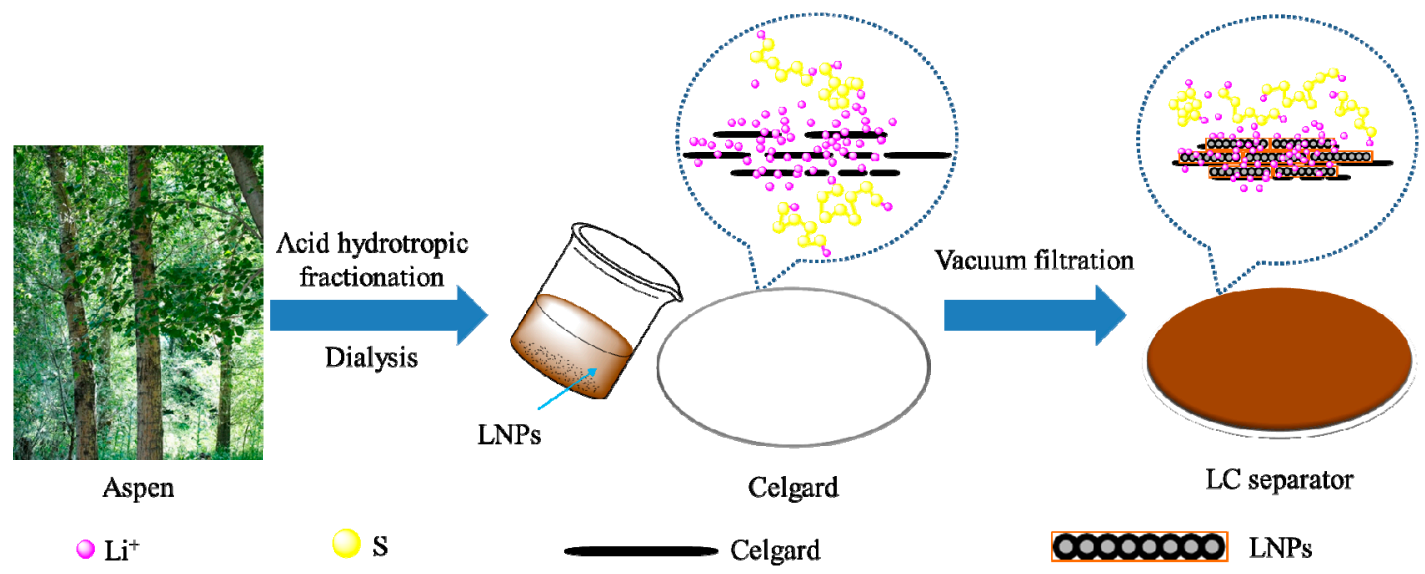

Figure 1. Schematic of the fabrication process to produce the lignin nanoparticle (LNP)-coated Celgard (LC) separator.

\subsection{Characterizations}

The Fourier transformed infrared (FTIR) spectrum of the LNPs was obtained on a commercial FTIR spectrometer (Nicolet 6700, Nicolet Instrument Co., Pittsburgh, PA, USA) over the wavenumber range of $4000-400 \mathrm{~cm}^{-1}$. A simultaneous thermogravimetric analysis (TGA)/differential scanning calorimetry (DSC) analyzer (TGA/DSC 3+, Mettler Toledo, Greifensee, Switzerland) was used to qualitatively analyze LNPs and quantitatively determine the sulfur content of the cathode. In detail, all samples were heated to $800^{\circ} \mathrm{C}$ at a heating rate of $10^{\circ} \mathrm{C} \cdot \mathrm{min}^{-1}$ under $\mathrm{N}_{2}$ atmosphere of $20 \mathrm{~mL} \cdot \mathrm{min}^{-1}$. The morphology and pore structure of the Celgard membrane and the LC separator were observed by a Hitachi SU8010 field emission scanning electron microscope (FESEM, Hitachi Co., Tokyo, Japan).

\subsection{Electrochemical Measurements}

For the electrochemical measurement, each cathode was prepared according to the method reported by Cai et al. [6], which is commonly used for Li-S batteries. In brief, sulfur powder was mixed with acetylene black and polyvinylidene fluoride (weight ratio of 8:1:1) in nmethyl-2-pyrrolidene under vigorous agitation. The mixed slurry was then moved onto a clean aluminum foil and vacuum dried at $60^{\circ} \mathrm{C}$ for $12 \mathrm{~h}$.

All cathode and separator samples were cut 12 and $16 \mathrm{~mm}$ in diameter, respectively. A standard cell assembly process for 2032 coin cells was carried out in an argon-filled glove box with a pair of cathode and metallic lithium anode separated by either LC separator or Celgard soaked with $20 \mu \mathrm{L}$ of electrolyte. Therefore, the amount of the electrolyte introduced to the cell corresponds to $23 \mathrm{~mL}$ of electrolyte per gram of sulfur. In addition, the electrolyte used in this study was of 1,3-dioxolane, and 1,2-dimethoxyethane $1: 1(v / v)$ with bis-(trifluoromethane) sulfonamide lithium $(1.0 \mathrm{M})$ and $1 \% \mathrm{LiNO}_{3}$.

The cells with different separators were galvanostatically discharged/charged between 1.7-2.8 V (VS Li/ $/ i^{+}$) at room temperature on a multichannel potentiostat system (Neware Battery Co., Shenzhen, China). The cyclic voltammetric and electrochemical impedance spectroscopy (EIS) measurements were performed on an electrochemical workstation (CHI760e, Chenhua Instruments, Shanghai, China). The EIS measurements were conducted at a frequency ranging from $10^{-2}$ to $10^{5} \mathrm{~Hz}$ at the AC amplitude of $5 \mathrm{mV}$ and an open circuit voltage. The specific capacity of the electrodes was calculated on the basis of the total weight of sulfur determined by TGA which was approximately $1.5 \mathrm{mg} \cdot \mathrm{cm}^{-2}$. 


\section{Results and Discussion}

\subsection{Structure of LNPS}

The FTIR was carried out to qualitatively confirm the presence of lignin in LNPs, and the peak assignments were conducted according to the literature $[37,41]$. As shown in Figure $2 \mathrm{a}$, the bands at 1610,1510 , and $1465 \mathrm{~cm}^{-1}$ are ascribed to $C=C$ benzene ring vibration, aromatic skeletal vibration, and asymmetric bending in $\mathrm{CH}_{3}$ of lignin, respectively. Though weaker than the ester group studied in Goodenough's [42] paper, the $\mathrm{C}=\mathrm{C}$ benzene ring and $\mathrm{CH}_{3}$ on $\mathrm{LNPs}$ were still of electron-donating groups and, thus, were expected to bind polysulfides to alleviate the shuttle effect. Figure $2 \mathrm{~b}$ shows that less than $2 \%$ of the weight of LNPs was lost in the range of $100-200{ }^{\circ} \mathrm{C}$ which indicates that the LNPs included very few volatiles. Also, a weight loss of about $37 \%$ that is attributed to the release of aromatics, carbonyls, alkyls, $\mathrm{CO}_{2}$, and $\mathrm{CO}$ was observed in the range of $200-500{ }^{\circ} \mathrm{C}$. Further, the characteristic feature that is ascribed to aspen-derived lignin between $200-500{ }^{\circ} \mathrm{C}$ [43] was observed as a weight loss peak at $384^{\circ} \mathrm{C}$ in the corresponding DTG curve in Figure 2.
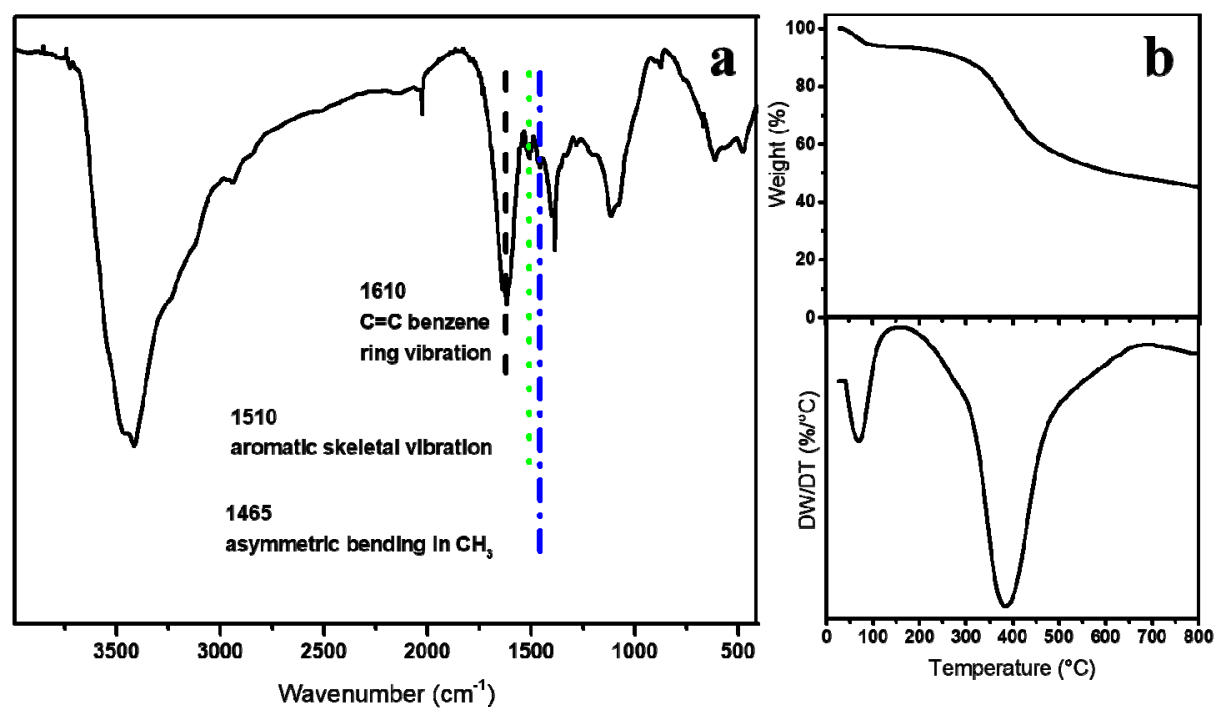

Figure 2. (a) FITR spectrum and (b) TGA curve of LNPs (upper) with corresponding DTG profiles (below).

\subsection{Pore Structures of Separators}

The FESEM images of pure Celgard and the LC separator are displayed in Figure 3a,b. It is clear that pure Celgard shows a macroporous arrangement in a representative elliptic shape (highlighted in Figure $3 b$ ) of an average semi-major axis/semi-minor axis of approximately 100/33 nm. For the LC separator, LNPs with an average diameter over $100 \mathrm{~nm}$ were found deposited on most macropores (Figure $3 c, d$ ). The latter is consistent with the fact that larger pores can retain more feedstocks which is common sense in the papermaking industry. Combining this with the above FTIR results, the electron-donating groups of LNPs on the LC separator were expected to induce chemical binding of polysulfides and restrict the polysulfides on the cathode. For a proof of concept, the diffusion behavior of polysulfides was observed in an H-type cell configuration with each of the two separators. As shown in Figure 3e-f, the cell with the Celgard separator underwent much severer polysulfides permeation which displayed a dark yellow color in the right chamber (the right unit in Figure 3f) after $24 \mathrm{~h}$ in contrast to the LC separator, half of whose right chamber (the left unit in Figure 3f) well maintained a clear and transparent appearance. That is, the LC-separator may comparably offer an enhanced capability to restrain the diffusion of polysulfides across it. In addition, the LC separator showed an unobvious immersion-height difference with respect to the Celgard separator (Figure $5 \mathrm{~g}$ ). This can be 
understood by the fact that LNPs coated on Celgard have no effect on its porosity (Figure 3a-d); thus, it has good electrolyte uptake performance [44].
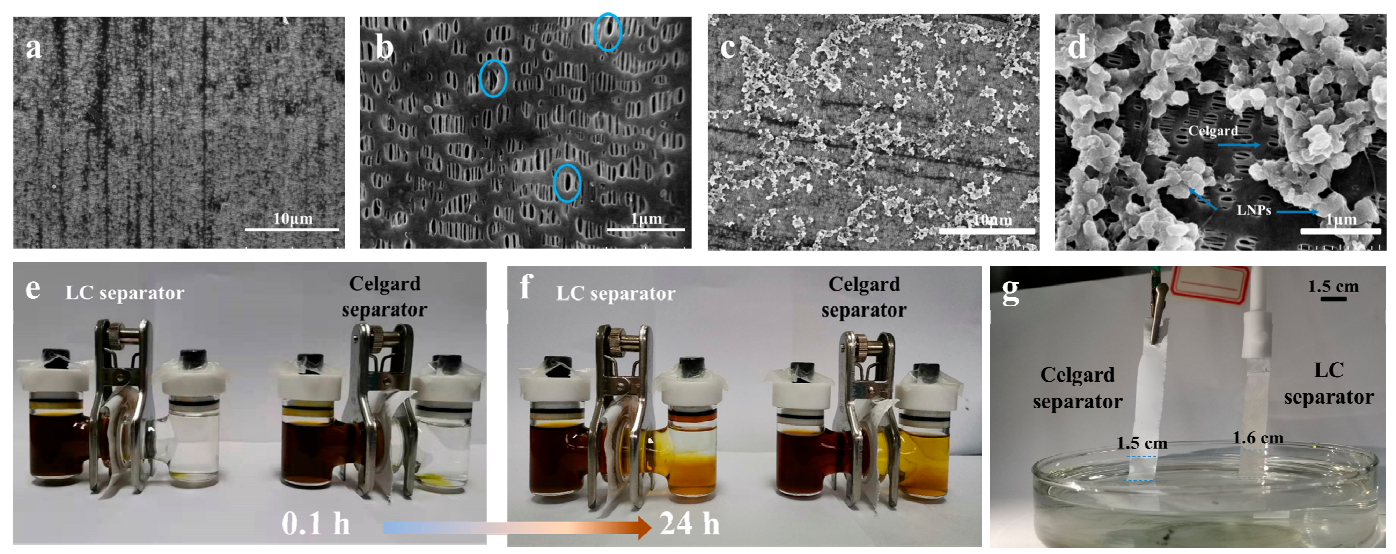

Figure 3. FESEM images of $(\mathbf{a}, \mathbf{b})$ the Celgard separator and (macropores highlighted by circles), (c,d) the LC separator, (e) optical observations of polysulfides diffusion (in both left chambers of the two units, initially $80 \mathrm{mg}$ of sulfur powder and $23 \mathrm{mg}$ of $\mathrm{Li}_{2} \mathrm{~S}$ were mixed in $20 \mathrm{~mL}$ of electrolyte under vigorous agitation in an argon-filled glove box in advance) when equipped with the LC separator (left unit) or the Celgard separator (right unit), (f) $24 \mathrm{~h}$ after (e), (g) photograph showing electrolyte immersion-height comparison between both separators after $60 \mathrm{~min}$, of which the dimension was fixed at $1.5 \mathrm{~cm} \times 18 \mathrm{~cm}$.

\subsection{Electrochemical and Long-Term Cycling Stability}

As shown by the typical CV curve at a scan rate of $0.1 \mathrm{mV} \cdot \mathrm{s}^{-1}$ (Figure $4 \mathrm{a}$ ), the reduction scan was composed of two cathodic peaks at 2.2 and $1.9 \mathrm{~V}$, representing reduction of the elemental sulfur to soluble high-order polysulfides $\left(\mathrm{Li}_{2} \mathrm{~S}_{\mathrm{n}}, 4 \leq \mathrm{n} \leq 8\right)$ and their further reduction to solid lithium sulfides $\left(\mathrm{Li}_{2} \mathrm{~S}_{2} / \mathrm{Li}_{2} \mathrm{~S}\right)$, respectively. This is much different from that of the neat Celgard separator (shown in Figure $4 \mathrm{~b}$ ). In the subsequent anodic scan, one oxidation peak at $2.5 \mathrm{~V}$ was discerned that related to the conversion of polysulfides to elemental sulfur [21,45] with facile electrochemical kinetics. As determined from the TGA curves presented in Figure 4c, a sharp weight loss was observed between 200 and $300^{\circ} \mathrm{C}$, corresponding to the evaporation of sulfur in the composite. That is, the sulfur content of the cells used in this study was estimated to be $73.8 \mathrm{wt} \%$ on the basis of which all the specific capacities of both separators addressed in the following were calculated. The rate performances with the LC separator and the Celgard separator were evaluated at various current rates from $0.1 \mathrm{C}$ to 2 C (Figure 4d). The cell armed with the Celgard separator suffered from dramatic capacity decay (the bottom curve) of which the specific capacity sharply decreased from the initial $167 \mathrm{mAh} \cdot \mathrm{g}^{-1}$ $(100 \%)$ to a final value of $140 \mathrm{mAh} \cdot \mathrm{g}^{-1}(83.8 \%)$. In contrast, the LC separator demonstrated much better performance (the middle curve) and the observed specific capacity only changed from the initial $380 \mathrm{mAh} \cdot \mathrm{g}^{-1}(228 \%)$ to the final $377 \mathrm{mAh} \cdot \mathrm{g}^{-1}(226 \%)$. Moreover, the LC separator could deliver initial capacities of 1006 (0.1 C), 777 (0.2 C), 603 (0.5 C), and 487 (1 C) $\mathrm{mAh}^{-1} \mathrm{~g}^{-1}$, outperforming 937 (0.1 C), $743(0.2 \mathrm{C}), 558(0.5 \mathrm{C})$, and $424(1 \mathrm{C}) \mathrm{mAh} \cdot \mathrm{g}^{-1}$ of the Celgard separator. 


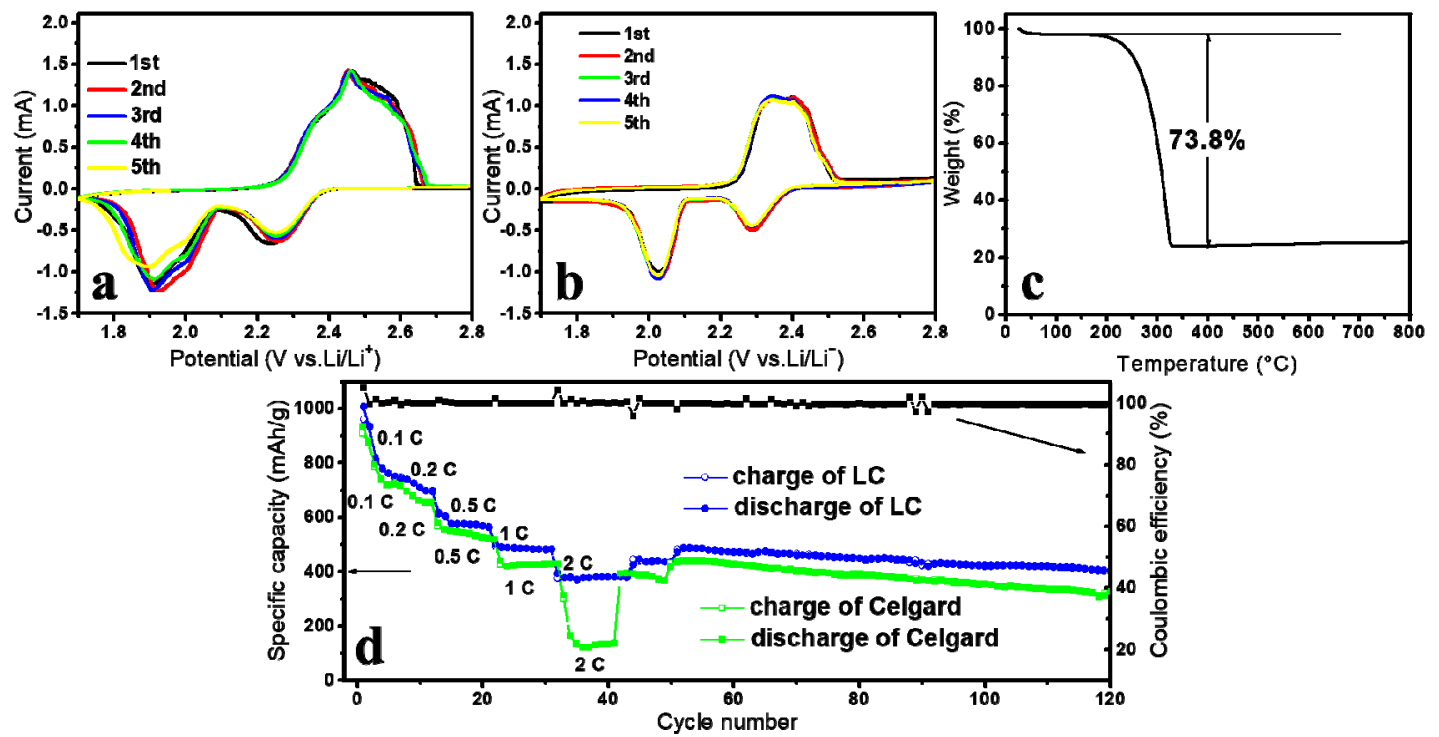

Figure 4. Cyclic voltammogram profile for Li-S battery with (a) the LC separator or (b) the Celgard separator at the scan rate of $0.1 \mathrm{mV} \cdot \mathrm{s}^{-1}$. (c) TGA curve of the cathode utilized in this study. (d) Rate performance at various current rates $(0.1,0.2,0.5,1$, and $2 \mathrm{C}$ ) with the LC separator (upper curves) or the Celgard separator (lower curves).

\subsection{Long-Term Cycling Stability}

For comparison purposes, the cycling stability of the LC separator and the Celgard separator was assessed at a current density of $1 \mathrm{C}$. Figure 5 a shows that two cells delivered close initial specific capacities ( $\left.450 \mathrm{mAh} \cdot \mathrm{g}^{-1}\right)$ and good coulombic efficiencies (>99\%). However, the capacity of the Celgard separator presented a significant $64.9 \%$ decrease in the subsequent 500 cycles, while this feature for the LC separator was only $34.8 \%$. The SEM images reveal that numerous macropores and mesopores existed in the Celgard separator, which was useless in retarding the polysulfides loss and, consequently, led to its poor cycling stability. In contrast, as confirmed above, the LC separator coated with LNPs could trap the polysulfides through chemical binding. The long-term cycling stability of the LC separator was further investigated by evaluating the evolution of over 660 charge/discharge cycles (Figure 5b). The first two cycles were performed at $0.1 \mathrm{C}$, and the subsequent 660 cycles were tested at $1 \mathrm{C}$. The initial discharge capacity of the LC separator was $405 \mathrm{mAh} \cdot \mathrm{g}^{-1}$ at $1 \mathrm{C}$, and its discharge capacity slowly decreased and ultimately reached $272 \mathrm{mAh} \cdot \mathrm{g}^{-1}$ after 660 cycles, which corresponded to a $0.168 \%$ capacity decay per cycle over 660 cycles. In most cases, the LC separator achieved a coulombic efficiency of over $99 \%$ which implies an excellent electrochemical reversibility. Figure $5 c, d$ presents several typical galvanostatic charge/discharge curves of both separators in long-term cycling at $1 \mathrm{C}$ which consisted of two reduction plateaus and one long oxidation plateau, representing the redox reactions of a typical Li-S battery. More information about capacity retention was obtained from these cycles. The capacity retentions of the LC separator were $100.8 \%$ after 100 cycles, $77.7 \%$ after 300 cycles, and $72.9 \%$ after 400 cycles, whereas the corresponding capacity retentions of the Celgard separator were $69.0 \%, 46.0 \%$, and $40.1 \%$. These results are consistent with the rate performance determination, indicating that the overwhelming cycling stability of the LC separator over the Celgard separator was maintained even at a high rate, especially considering that the discharge plateau voltage of the LC separator stabilized around $\sim 2.0 \mathrm{~V}$. The EIS measurements were conducted to further demonstrate the electron and ion transfer capability of these separators. As shown in Figure 5e, the charge transfer resistance $\left(R_{\mathrm{ct}}\right.$, corresponding to the diameter of the semicircle at high frequencies) was 27 and $87 \Omega$ for the LC separator and Celgard separator, respectively. The smaller $\mathrm{R}_{\mathrm{ct}}$ for the LC separator suggests a fast lithium ion diffusion in the LC separator which might be attributed to the electron-donating groups of LNPs on the LC separator that can induce chemical binding of polysulfides and restrict the 
polysulfides on the cathode, ensuring their better contact than the Celgard separator. Moreover, it was found that this benefit of the LC separator would be compromised when the LNPs loading increased to $3.20 \mathrm{~g} \cdot \mathrm{cm}^{-2}$ which confirmed the above speculation, because higher LNP loading usually leads to severer agglomeration (Figure 5e).
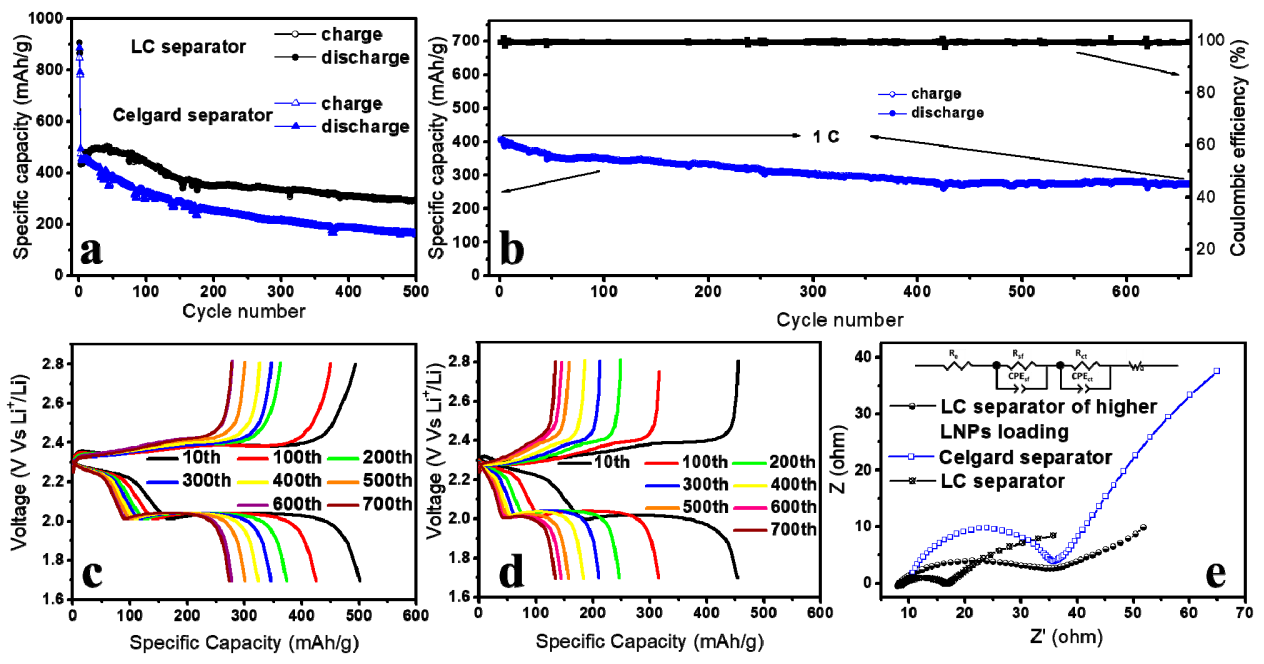

Figure 5. (a) Cycling stability comparison between the LC separator and the Celgard separator at a current rate of $1 \mathrm{C} ;(\mathbf{b})$ cycling stability and coulombic efficiency at a current rate of $1 \mathrm{C}$ over 660 cycles with the LC separator; galvanostatic charge/discharge curves of (c) the LC separator and (d) the Celgard separator, (both at the current rate of 1 C); (e) Nyquist plots from the EIS of fresh cells with the LC separator of higher LNP loading $\left(3.20 \mathrm{~g} \cdot \mathrm{cm}^{-2}\right)$, the Celgard separator, and the LC separator.

\section{Conclusions}

Biomass-derived lignin nanoparticles were prepared through a green acid hydrotrope method and successfully coated onto Celgard membrane. We demonstrated that a lignin nanoparticle-coated Celgard separator could alleviate the shuttle effect. On one hand, LNPs can serve as a temporary electrolyte reservoir to restrain the soluble polysulfides from directly diffusing into the bulk electrolyte. On the other hand, LNPs have abundant electron-donating groups that can induce chemical binding of polysulfidesand consequently improve the cycling stability. The strategy demonstrated in this work will open the door toward developing efficient biomass-derived separators using green chemistry for the practical applications of energy storage devices.

Author Contributions: Conceptualization, Z.Z., S.Y., and Y.W.; methodology, Z.Z., H.B. and R.W.; software, Z.Z.; validation, Z.Z., and S.Y.; investigation, Z.Z., and S.Y.; resources, R.W., and Y.M.; data curation, R.W., writing-original draft preparation, R.W., and Y.M.; supervision, Y.M.; project administration, Y.M.; funding acquisition, R.W. and Y.M.

Funding: This work was supported by the Program for Guangdong Introducing Innovative and Entrepreneurial Research Team (2016ZT06C412), the Hundred Talent Program of Guangdong University of Technology (220418095), the Postdoctoral Science Foundation of China and the Open Fund of Jiangsu Provincial Key Lab of Pulp and Paper Science and Technology (KL201908).

Conflicts of Interest: The authors declare no conflict of interest.

\section{References}

1. Bai, S.; Liu, X.; Zhu, K.; Wu, S.; Zhou, H. Metal-organic framework-based separator for lithium-sulfur batteries. Nat. Energy 2016, 1, 16094. [CrossRef]

2. Zhou, G.; Li, L.; Wang, D.W.; Shan, X.y.; Pei, S.; Li, F.; Cheng, H.M. A flexible sulfur-graphene-polypropylene separator integrated electrode for advanced Li-S batteries. Adv. Mater. 2015, 27, 641-647. [CrossRef] [PubMed] 
3. Lu, L.; Han, X.; Li, J.; Hua, J.; Ouyang, M. A review on the key issues for lithium-ion battery management in electric vehicles. J. Power Sources 2013, 226, 272-288. [CrossRef]

4. Yin, Y.X.; Xin, S.; Guo, Y.G.; Wan, L.J. Lithium-sulfur batteries: Electrochemistry, materials, and prospects. Angew. Chem. Int. Ed. 2013, 52, 13186-13200. [CrossRef] [PubMed]

5. Bruce, P.G.; Freunberger, S.A.; Hardwick, L.J.; Tarascon, J.-M. Li-O 2 and Li-S batteries with high energy storage. Nat. Mater. 2012, 11, 19. [CrossRef]

6. Cai, J.; Zhang, Z.; Yang, S.; Min, Y.; Yang, G.; Zhang, K. Self-conversion templated fabrication of sulfur encapsulated inside the $\mathrm{N}$-doped hollow carbon sphere and 3D graphene frameworks for high-performance lithium-sulfur batteries. Electrochim. Acta 2019, 295, 900-909. [CrossRef]

7. Cai, J.; Wu, C.; Yang, S.; Zhu, Y.; Shen, P.K.; Zhang, K. Templated and Catalytic Fabrication of N-Doped Hierarchical Porous Carbon-Carbon Nanotube Hybrids as Host for Lithium-Sulfur Batteries. ACS Appl. Mater. Interfaces 2017, 9, 33876-33886. [CrossRef]

8. Huang, Y.; Zheng, M.; Lin, Z.; Zhao, B.; Zhang, S.; Yang, J.; Zhu, C.; Zhang, H.; Sun, D.; Shi, Y. Flexible cathodes and multifunctional interlayers based on carbonized bacterial cellulose for high-performance lithium-sulfur batteries. J. Mater. Chem A 2015, 3, 10910-10918. [CrossRef]

9. Cai, J.; Li, Z.; Shen, P.K. Porous SnS nanorods/carbon hybrid materials as highly stable and high capacity anode for Li-ion batteries. ACS Appl. Mater. Interfaces 2012, 4, 4093-4098. [CrossRef]

10. Cai, J.; Wu, C.; Zhu, Y.; Zhang, K.; Shen, P.K. Sulfur impregnated N, P co-doped hierarchical porous carbon as cathode for high performance Li-S batteries. J. Power Sources 2017, 341, 165-174. [CrossRef]

11. Zhou, G.; Wang, D.-W.; Li, F.; Hou, P.-X.; Yin, L.; Liu, C.; Lu, G.Q.M.; Gentle, I.R.; Cheng, H.-M. A flexible nanostructured sulphur-carbon nanotube cathode with high rate performance for Li-S batteries. Energy Environ. Sci. 2012, 5, 8901-8906. [CrossRef]

12. Xiao, L.; Cao, Y.; Xiao, J.; Schwenzer, B.; Engelhard, M.H.; Saraf, L.V.; Nie, Z.; Exarhos, G.J.; Liu, J. A Soft Approach to Encapsulate Sulfur: Polyaniline Nanotubes for Lithium-Sulfur Batteries with Long Cycle Life. Adv. Mater. 2012, 24, 1176-1181. [CrossRef] [PubMed]

13. Wu, B.; Jiang, X.; Xiao, L.; Zhang, W.; Pan, J.; Ai, X.; Yang, H.; Cao, Y. Enhanced Cycling Stability of Sulfur Cathode Surface-Modified by Poly(N-methylpyrrole). Electrochim. Acta 2014, 135, 108-113. [CrossRef]

14. He, J.; Chen, Y.; Manthiram, A. MOF-derived cobalt sulfide grown on 3D graphene foam as an efficient sulfur host for long-life lithium-sulfur batteries. iScience 2018, 4, 36-43. [CrossRef]

15. He, J.; Chen, Y.; Manthiram, A. Metal Sulfide-Decorated Carbon Sponge as a Highly Efficient Electrocatalyst and Absorbant for Polysulfide in High-Loading Li2S Batteries. Adv. Energy Mater. 2019, 9, 1900584. [CrossRef]

16. He, J.; Hartmann, G.; Lee, M.; Hwang, G.S.; Chen, Y.; Manthiram, A. Freestanding $1 \mathrm{~T} \mathrm{MoS}_{2} /$ graphene $^{2}$ heterostructures as a highly efficient electrocatalyst for lithium polysulfides in Li-S batteries. Energy Environ. Sci. 2019, 12, 344-350. [CrossRef]

17. He, J.; Luo, L.; Chen, Y.; Manthiram, A. Yolk-Shelled C@ $\mathrm{Fe}_{3} \mathrm{O}_{4}$ Nanoboxes as Efficient Sulfur Hosts for High-Performance Lithium-Sulfur Batteries. Adv. Mater. 2017, 29, 1702707. [CrossRef]

18. Zhang, Z.; Lai, Y.; Zhang, Z.; Zhang, K.; Li, J. Al2O3-coated porous separator for enhanced electrochemical performance of lithium sulfur batteries. Electrochim. Acta 2014, 129, 55-61. [CrossRef]

19. Peng, H.-J.; Wang, D.-W.; Huang, J.-Q.; Cheng, X.-B.; Yuan, Z.; Wei, F.; Zhang, Q. Janus Separator of Polypropylene-Supported Cellular Graphene Framework for Sulfur Cathodes with High Utilization in Lithium-Sulfur Batteries. Adv. Sci. 2016, 3, 1500268. [CrossRef]

20. Zhuang, T.Z.; Huang, J.Q.; Peng, H.J.; He, L.Y.; Cheng, X.B.; Chen, C.M.; Zhang, Q. Rational integration of polypropylene/graphene oxide/nafion as ternary-layered separator to retard the shuttle of polysulfides for lithium-sulfur batteries. Small 2016, 12, 381-389. [CrossRef]

21. Ghazi, Z.A.; He, X.; Khattak, A.M.; Khan, N.A.; Liang, B.; Iqbal, A.; Wang, J.; Sin, H.; Li, L.; Tang, Z. MoS2/Celgard separator as efficient polysulfide barrier for long-life lithium-sulfur batteries. Adv. Mater. 2017, 29, 1606817. [CrossRef] [PubMed]

22. He, J.; Chen, Y.; Manthiram, A. Vertical Co 9 S 8 hollow nanowall arrays grown on a Celgard separator as a multifunctional polysulfide barrier for high-performance Li-S batteries. Energy Environ. Sci. 2018, 11, 2560-2568. [CrossRef]

23. Bauer, I.; Thieme, S.; Brückner, J.; Althues, H.; Kaskel, S. Reduced polysulfide shuttle in lithium-sulfur batteries using Nafion-based separators. J. Power Sources 2014, 251, 417-422. [CrossRef] 
24. Jin, Z.; Xie, K.; Hong, X.; Hu, Z.; Liu, X. Application of lithiated Nafion ionomer film as functional separator for lithium sulfur cells. J. Power Sources 2012, 218, 163-167. [CrossRef]

25. Lin, C.; Zhang, W.; Wang, L.; Wang, Z.; Zhao, W.; Duan, W.; Zhao, Z.; Liu, B.; Jin, J. A few-layered $\mathrm{Ti}_{3} \mathrm{C}_{2}$ nanosheet/glass fiber composite separator as a lithium polysulphide reservoir for high-performance lithium-sulfur batteries. J. Mater. Chem A 2016, 4, 5993-5998. [CrossRef]

26. Lin, W.; Chen, Y.; Li, P.; He, J.; Zhao, Y.; Wang, Z.; Liu, J.; Qi, F.; Zheng, B.; Zhou, J. Enhanced performance of lithium sulfur battery with a reduced graphene oxide coating separator. J. Electrochem. Soc. 2015, 162, A1624-A1629. [CrossRef]

27. Huang, C.; Wang, X.; Liang, C.; Jiang, X.; Yang, G.; Xu, J.; Yong, Q. A sustainable process for procuring biologically active fractions of high-purity xylooligosaccharides and water-soluble lignin from Moso bamboo prehydrolyzate. Biotechnol. Biofuels 2019, 12, 189. [CrossRef]

28. Wang, R.; Xia, G.; Zhong, W.; Chen, L.; Chen, L.; Wang, Y.; Min, Y.; Li, K. Direct transformation of lignin into fluorescence-switchable graphene quantum dots and their application in ultrasensitive profiling of a physiological oxidant. Green Chem. 2019, 21, 3343-3352. [CrossRef]

29. Chen, L.; Zhou, X.; Shi, Y.; Gao, B.; Wu, J.; Kirk, T.B.; Xu, J.; Xue, W. Green synthesis of lignin nanoparticle in aqueous hydrotropic solution toward broadening the window for its processing and application. Chem. Eng. J. 2018, 346, 217-225. [CrossRef]

30. Wang, Q.; Pan, X.; Lin, C.; Lin, D.; Ni, Y.; Chen, L.; Huang, L.; Cao, S.; Ma, X. Biocompatible, self-wrinkled, antifreezing and stretchable hydrogel-based wearable sensor with PEDOT: Sulfonated lignin as conductive materials. Chem. Eng. J. 2019, 370, 1039-1047. [CrossRef]

31. Jędrzak, A.; Rębiś, T.; Klapiszewski, Ł.; Zdarta, J.; Milczarek, G.; Jesionowski, T. Carbon paste electrode based on functional GOx/silica-lignin system to prepare an amperometric glucose biosensor. Sens. Actuators B Chem. 2018, 256, 176-185. [CrossRef]

32. Wu, Y.; Wang, J.; Qiu, X.; Yang, R.; Lou, H.; Bao, X.; Li, Y. Highly efficient inverted perovskite solar cells with sulfonated lignin doped PEDOT as hole extract layer. ACS Appl. Mater. Interfaces 2016, 8, 12377-12383. [CrossRef] [PubMed]

33. Geng, X.; Zhang, Y.; Jiao, L.; Yang, L.; Hamel, J.; Giummarella, N.; Henriksson, G.; Zhang, L.; Zhu, H. Bioinspired Ultrastable Lignin Cathode via Graphene Reconfiguration for Energy Storage. ACS Sustain. Chem. Eng. 2017, 5, 3553-3561. [CrossRef]

34. Lai, C.; Zhou, Z.; Zhang, L.; Wang, X.; Zhou, Q.; Zhao, Y.; Wang, Y.; Wu, X.-F.; Zhu, Z.; Fong, H. Free-standing and mechanically flexible mats consisting of electrospun carbon nanofibers made from a natural product of alkali lignin as binder-free electrodes for high-performance supercapacitors. J. Power Sources 2014, 247, 134-141. [CrossRef]

35. Ma, Y.; Chen, K.; Ma, J.; Xu, G.; Dong, S.; Chen, B.; Li, J.; Chen, Z.; Zhou, X.; Cui, G. A biomass based free radical scavenger binder endowing a compatible cathode interface for $5 \mathrm{~V}$ lithium-ion batteries. Energy Environ. Sci. 2019, 12, 273-280. [CrossRef]

36. Li, Y.; Hu, Y.-S.; Li, H.; Chen, L.; Huang, X. A superior low-cost amorphous carbon anode made from pitch and lignin for sodium-ion batteries. J. Mater. Chem. A 2016, 4, 96-104. [CrossRef]

37. Bian, H.; Chen, L.; Gleisner, R.; Dai, H.; Zhu, J.Y. Producing wood-based nanomaterials by rapid fractionation of wood at $80^{\circ} \mathrm{C}$ using a recyclable acid hydrotrope. Green Chem. 2017, 19, 3370-3379. [CrossRef]

38. Chen, L.; Dou, J.; Ma, Q.; Li, N.; Wu, R.; Bian, H.; Yelle, D.J.; Vuorinen, T.; Fu, S.; Pan, X. Rapid and near-complete dissolution of wood lignin at $\leq 80 \mathrm{C}$ by a recyclable acid hydrotrope. Sci. Adv. 2017, 3, e1701735. [CrossRef]

39. Lee, H.; Alcoutlabi, M.; Toprakci, O.; Xu, G.; Watson, J.V.; Zhang, X. Preparation and characterization of electrospun nanofiber-coated membrane separators for lithium-ion batteries. J. Solid State Electrochem. 2014, 18, 2451-2458. [CrossRef]

40. Lee, H.; Alcoutlabi, M.; Watson, J.V.; Zhang, X. Electrospun nanofiber-coated separator membranes for lithium-ion rechargeable batteries. J. Appl. Polym. Sci. 2013, 129, 1939-1951. [CrossRef]

41. Colom, X.; Carrillo, F.; Nogués, F.; Garriga, P. Structural analysis of photodegraded wood by means of FTIR spectroscopy. Polym. Degrad. Stab. 2003, 80, 543-549. [CrossRef]

42. Park, K.; Cho, J.H.; Jang, J.-H.; Yu, B.-C.; Andreah, T.; Miller, K.M.; Ellison, C.J.; Goodenough, J.B. Trapping lithium polysulfides of a Li-S battery by forming lithium bonds in a polymer matrix. Energy Environ. Sci. 2015, 8, 2389-2395. [CrossRef] 
43. Zhang, M.; Resende, F.L.P.; Moutsoglou, A.; Raynie, D.E. Pyrolysis of lignin extracted from prairie cordgrass, aspen, and Kraft lignin by Py-GC/MS and TGA/FTIR. J. Anal. Appl. Pyrolysis 2012, 98, 65-71. [CrossRef]

44. Sheng, J.; Chen, T.; Wang, R.; Zhang, Z.; Hua, F.; Yang, R. Ultra-light cellulose nanofibril membrane for lithium-ion batteries. J. Membr. Sci. 2019, 117550. [CrossRef]

45. Li, Z.; Zhang, J.; Wu, H.B.; Lou, X.W. An Improved Li-SeS2 Battery with High Energy Density and Long Cycle Life. Adv. Energy Mater. 2017, 7, 1700281. [CrossRef]

(C) 2019 by the authors. Licensee MDPI, Basel, Switzerland. This article is an open access article distributed under the terms and conditions of the Creative Commons Attribution (CC BY) license (http://creativecommons.org/licenses/by/4.0/). 